\title{
Ultra-wideband outdoor communication characteristics with and without traffic
}

\author{
Chien-Ching Chiu ${ }^{{ }^{*}}$, Chien-Hung Chen ${ }^{2}$, Shu-Han Liao ${ }^{1}$ and Ting-Chieh Tu${ }^{1}$
}

\begin{abstract}
The BER performance for ultra-wideband (UWB) outdoor communication in LOS and NLOS environments with and without traffic is investigated. We obtain the impulse responses of the UWB outdoor environment by both 2.5D SBR-Image method and inverse Fourier transform techniques. The 2.5D SBR-Image method is first considered for two-dimensional environment simulated without heights of obstacles by ray tubes. Then, heights of the obstacles are taken into consideration between the transmitters and receivers. If the height of ray is lower than that of obstacles, the ray is neglected for the receivers. This effectively reduces the simulating time. By using the impulse response of multipath channels, the BER performance for binary pulse amplitude modulation communications over the radio UWB system is evaluated. We have performed computer simulations in LOS and NLOS environments with and without traffic in dense building areas. Numerical results have shown that the multipath effect caused by moving vehicles in the outdoor LOS and NLOS environments has a great impact on BER performance. Rake receivers are used to improve the outage probability. The relationship between traffic and BER performance is investigated; meanwhile, the characteristics of LOS and NLOS outdoor UWB environments are analyzed. Our investigation results can help improve planning and design of the UWB system.
\end{abstract}

Keywords: UWB, multipath, BER, outage probability, RMS delay spread

\section{Introduction}

When the Federal Communications Commission agreed in February 2002 to allocate the $7500 \mathrm{MHz}$ bandwidth for unlicensed use of ultra-wideband (UWB) communications in the 3.1-10.6 GHz frequency region [1], the UWB technology has received wide research attention ever since. There are two task groups for Ultra UWB systems. One is the $802.15 .3 \mathrm{a}$ for high data rate $(100 \mathrm{M} /$ bps) and short operation distance $(10 \mathrm{~m})$. The other one is 802.15.4a for lower data rate $(2 \mathrm{M} / \mathrm{bps})$ and longer propagation distance (up to $100 \mathrm{~m}$ ) [2].

UWB system offers many potential advantages, such as high resolution in multipath, reducing fading margins in link budget analysis, allowing for low transmit powers and low complexity $[3,4]$. All wireless systems must be able to deal with the challenges of operating over a multipath propagation channel, where objects in outdoor environment can cause multiple reflections and shadow

\footnotetext{
* Correspondence: chiu@ee.tku.edu.tw

'Electrical Engineering Department, Tamkang University, Tamsui Dist, New Taipei City 25137, Taiwan

Full list of author information is available at the end of the article
}

effect. The bit error rate (BER) degradation is caused by intersymbol interference (ISI) due to a multipath propagation arising from radio wave reflections by buildings, vehicles, trees, and even pedestrians. Recently, UWB has become an alternative physical layer candidate for TG4a in 802.15. In this task group, the emphasis is on lower data rates with larger propagation range in outdoor environment. In this study, we shall focus on this task group and investigate the outdoor environment performance $[5,6]$. We shall use ray tracing techniques and inverse Fourier transform to obtain the impulse for UWB outdoor communications and evaluate the BER performance for binary pulse amplitude modulation (BPAM) communications over radio (IR) UWB systems with and without traffic. Section 2 presents channel modeling and system description. Section 3 shows numerical results. Conclusions are drawn in Section 4.

\section{Channel modeling and system description 2.1. Channel modeling}

The following two steps are used to model the multipath radio channel.
(C) 2012 Chiu et al; licensee Springer. This is an Open Access article distributed under the terms of the Creative Commons Attribution License (http://creativecommons.org/licenses/by/2.0), which permits unrestricted use, distribution, and reproduction in any medium, provided the original work is properly cited. 


\section{(1) Frequency responses for sinusoidal waves using the SBR/Image technique}

The SBR/Image method can deal with high-frequency radio wave propagation in the complex indoor environment $[7,8]$. It conceptually assumes that many triangular ray tubes are shot from the transmitting antenna (TX), and each ray tube, bouncing and penetrating in the environment is traced in the indoor multipath channel. If the receiving antenna $(\mathrm{RX})$ is within a ray tube, the ray tube will produce image contributions to the received field at the $\mathrm{RX}$, and the corresponding equivalent source (image) can be determined. By summing all contributions of these images, we can obtain the total received field at the RX. In the real environment, external noise in the channel propagation will be considered. The depolarization yielded by multiple reflections, refraction, and first-order diffraction, is also taken into account in our simulations. Note that the different values of dielectric constant and conductivity of materials for different frequencies are carefully considered in channel modeling.

Using ray-tracing techniques to predict channel characteristic is effective and fast [7-9]. Thus, a ray-tracing channel model is used to calculate the channel matrix of the UWB system. The flow chart of the ray-tracing process is shown in Figure 1. It conceptually assumes that many triangular ray tubes (not rays) are shot from a transmitter. Here, the triangular ray tubes whose vertexes are on a sphere are determined by the following method. First, we construct an icosahedron which is made of 20 identical equilateral triangles. Then, each triangle of the icosahedron is tessellated into many smaller equilateral triangles. Finally, these small triangles are projected onto the sphere and each ray tube whose vertexes are determined by the small equilateral triangle is constructed.

For each ray tube bouncing and penetrating in the environment, we check whether reflection and penetration times of the ray tube are larger than the number of maximum reflection $N_{\text {ref }}$ and maximum penetration $N_{\text {pen }}$, respectively. If not, we check whether the receiver falls within the reflected ray tube. If yes, the contribution of the ray tube to the receiver can be assumed to be emitted from an equivalent image source. In other words, a specular ray going to receiver is assumed to exist in this tube and this ray can be thought as launched from an image source. Moreover, the field diffracted from illuminated wedges of the objects in the environment is calculated by uniform theory of diffraction [10]. Note that only first diffraction is considered in this article, because the contribution of second diffraction is very small in the analysis.

By using these images and received fields, the channel frequency response can be obtained as follows:

$$
H(f)=\sum_{p=1}^{N_{\mathrm{p}}} a_{p}(f) e^{j \theta_{p}(f)}
$$

where $p$ is the path index, $N_{\mathrm{p}}$ is the number of paths, $f$ is the frequency of sinusoidal wave, $\theta_{p}(f)$ is the $p$ th phase shift, and $a_{p}(f)$ is the $p$ th amplitude. Note that the channel frequency response of UWB systems can be calculated by Equation (1) in the frequency range of UWB for both desired and interference signals.

\section{(2) Inverse Fast Fourier Transform (IFFT) and Hermitian Processing}

The frequency response can be transformed to the time domain by using the inverse Fourier transform with the Hermitian signal processing [11]. By using the Hermitian processing, the pass-band signal is obtained with zero padding from the lowest frequency down to direct current (DC), taking the conjugate of the signal, and reflecting it to the negative frequencies. The result is then transformed to the time domain using IFFT [12]. Since the signal spectrum is symmetric around DC, the resultant doubled sideband spectrum corresponds to a real signal in the time domain.

The equation used to model the multipath radio channel is a linear filter with an equivalent impulse response given by

$$
h_{b}(t)=\sum_{l=1}^{N} \alpha_{l} \delta\left(t-\tau_{l}\right)
$$

where $l$ is the path index, $\alpha_{l}$ is the amplitude of $l$ th path and $\tau_{l}$ is the time delay of the $l$ th path. $\delta($.$) is the$ Dirac delta function [13]. The goal of channel modeling is to determine the $\alpha_{l}$ and $\tau_{l}$ for a transmitter-receiver location in the system. The impulse response function of the station for a transmitter-receiver location is computed by the following two steps: step one is the obtaining of frequency response for sinusoidal waves by the SBR/Image technique and step two is the use of IFFT and Hermitian processing [14].

The SBR/Image method can deal with high-frequency radio wave propagation in the complex outdoor environment. It conceptually assumes that many ray tubes are short from the transmitting antenna (TX) and each ray tube bouncing and penetrating in the environment is traced. The first-order wedge diffraction is included, and the diffracted rays are attributed to the corresponding image. A frequency response is transformed to the time domain by using inverse Fourier transform with Hermitian signal processing. Using Hermitian processing, the pass-band signal is obtained with zero padding from the lowest frequency down to DC, taking the conjugate of the signal, and reflecting it to the negative frequencies. The result is then transformed to the time 


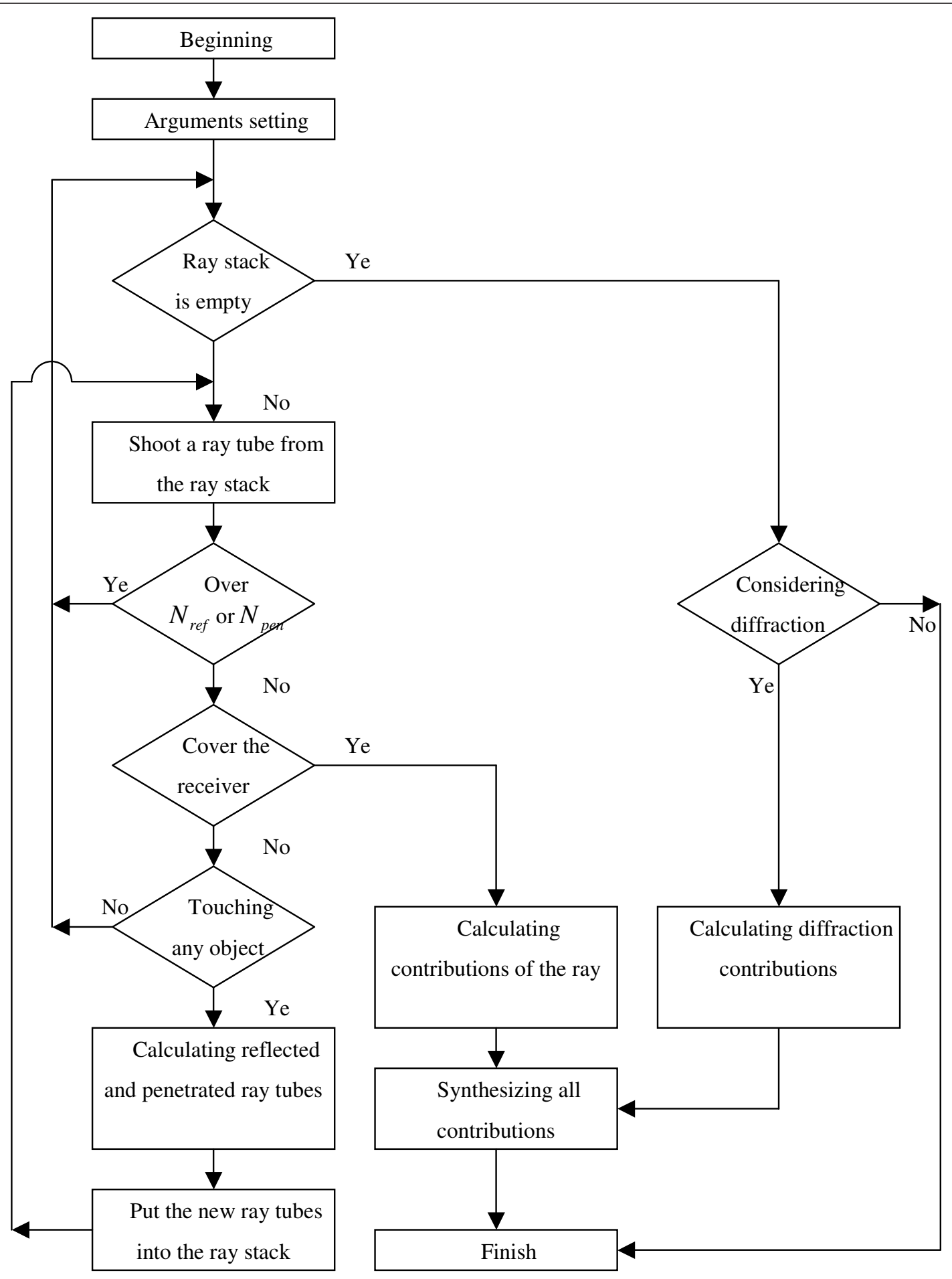

Figure 1 Flow chart of the ray-tracing process. 


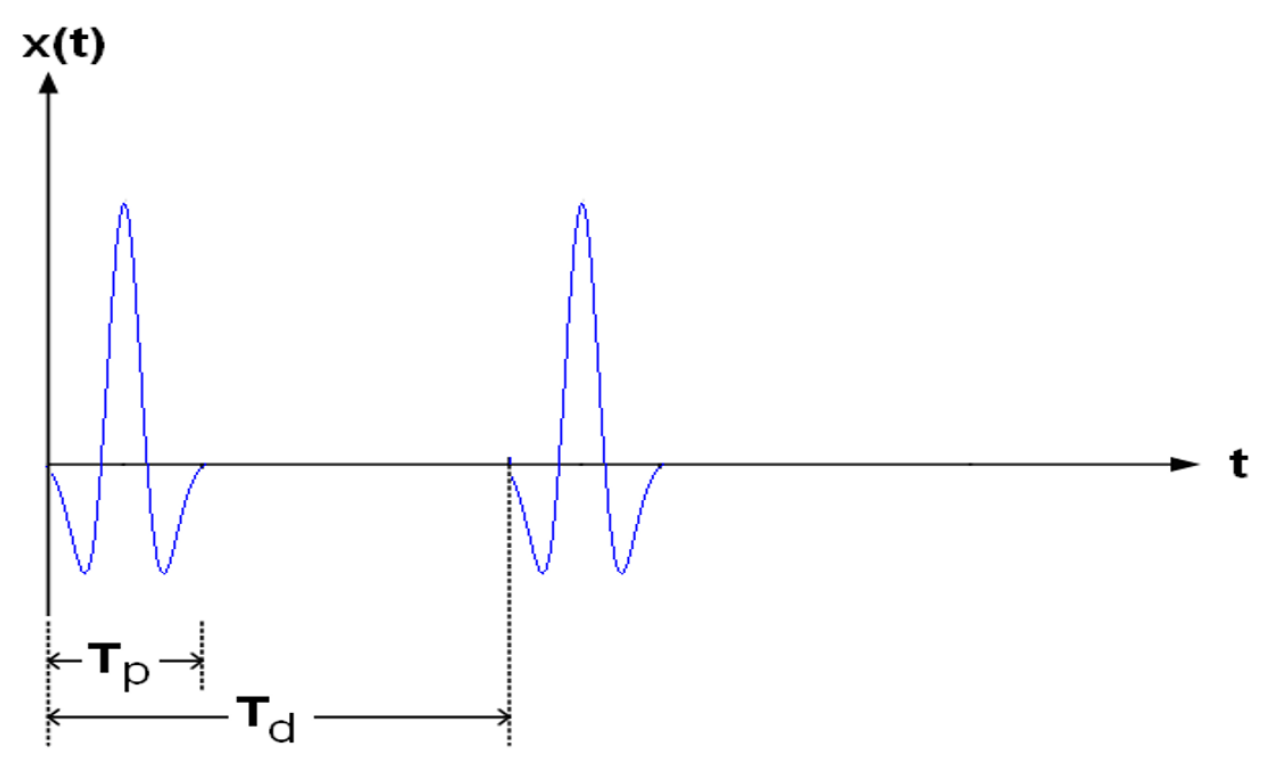

Figure 2 The diagram of transmitted waveform.

domain by using IFFT. Since the signal spectrum is symmetric around DC, the resultant doubled-side spectrum corresponds to a real signal in the time domain.

\subsection{System block diagram}

The diagram of transmitted waveform is shown in Figure 2. The transmitted UWB pulse stream can be expressed as [15-24]:

$$
x(t)=\sqrt{E_{\mathrm{TX}}} \sum_{n=0}^{\infty} p\left(t-n T_{\mathrm{d}}\right) d_{n}
$$

where $E_{\mathrm{TX}}$ is the average transmitted energy symbol and $p(t)$ is the second derivative of the Gaussian waveform. $T_{\mathrm{d}}$ is the duration of the transmitted signal. The binary PAM symbol $d_{n} \in\{ \pm 1\}$ is assumed to be independent, identically distributed (i.i.d.). The waveform $p(t)$ has an ultra-short duration $T_{p}$ usually of the order of nanoseconds and is usually much smaller than $T_{\mathrm{d}}$. The waveform $p(t)$ can be described by the following expression:

$$
p(t)=\frac{d^{2}}{d t^{2}}\left(\frac{1}{\sqrt{2 \pi} \sigma} e^{\frac{-t^{2}}{2 \sigma^{2}}}\right)
$$

where $t$ and $\sigma$ are time and standard deviation of the Gaussian wave, respectively.

The average transmitted energy symbol $E_{\mathrm{TX}}$ can be expressed as

$$
E_{\mathrm{TX}}=\int_{0}^{T_{d}} p^{2}(t) d t
$$

Block diagram of the simulated communication system is shown in Figure 3. The received signal after the bandpass filter $r(t)$ can be expressed as follows:

$$
r(t)=\left[x(t) \otimes h_{b}(t)\right]+n(t)
$$

where $x(t)$ is the transmitted signal and $h_{b}(t)$ is the impulse response of the UWB channel, $n(t)$ is the white Gaussian noise with zero mean and power spectral density $N_{0} / 2 \mathrm{w} / \mathrm{Hz}$.

The correlation receiver samples the received signal at the symbol rate with a delay given by

$$
q(t)=p\left(t-\tau_{1}-n T_{\mathrm{d}}\right)
$$

where $\tau_{1}$ is the delay time of the first received wave. The output of the correlator is

$$
Z_{n}=\int_{0}^{T_{d}}\left\{\left[\sqrt{E_{\mathrm{TX}}} \sum_{n=0}^{\infty} p\left(t-n T_{\mathrm{d}}\right) d_{n}\right] \otimes h_{b}(t)\right\} \cdot q(t) d t+\int_{0}^{T_{d}} n(t) q(t) d t=V_{n}+\eta
$$

It can be shown that the noise components $\eta$ of Equation (8) are uncorrelated Gaussian variables with zero mean. The variance of the output noise $\eta$ is

$$
\sigma^{2}=\frac{N_{0}}{2} E_{\mathrm{TX}}
$$

The average probability of error is thus expressed by:

$$
P_{e}\left[Z\left(t=n T_{\mathrm{d}}\right) \mid \vec{d}_{n}\right]=\frac{1}{2} \operatorname{erfc}\left[\frac{V\left(t=n T_{\mathrm{d}}\right)}{\sqrt{2} \sigma} \cdot\left(d_{n}\right)\right]
$$




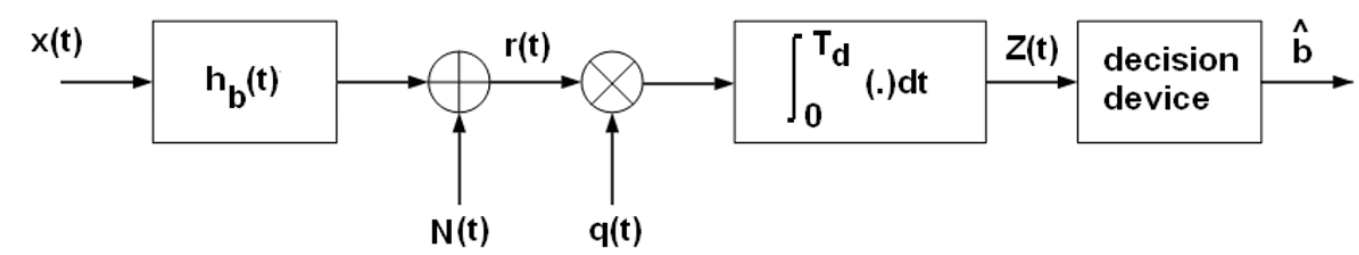

Figure 3 Block diagram of the simulated communication system.

where $\operatorname{erfc}(x)=2 / \sqrt{\pi} \int_{x}^{\infty} e^{-y^{2}} d y$ is the complementary error function and $\left\{\vec{d}_{n}\right\}=\left\{d_{0}, d_{1}, \ldots, d_{N}\right\}$ is the binary sequence. Finally, the BER for the BPAM IR UWB system can be expressed as

$$
\mathrm{BER}=\sum_{n=0}^{N} P\left(\vec{d}_{n}\right) \cdot \frac{1}{2} \operatorname{erfc}\left[\frac{V\left(t=n T_{\mathrm{d}}\right)}{\sqrt{2} \sigma} \cdot\left(d_{n}\right)\right]
$$

\subsection{RMS delay spread and mean excess delay}

In order to compare different multipath channels and develop general design guidelines for wireless systems, parameters which grossly quantify the multipath channel are used. The mean excess delay spread and root mean square (RMS) delay spread are parameters of the multipath channel that can be determined from a power delay profile or channel impulse response. However, the time dispersive properties of wideband multipath channels are most commonly quantified by their mean excess delay and RMS delay spread. The mean excess delay is defined as

$$
\bar{\tau}=\frac{\sum_{k} \beta_{k}^{2} \tau_{k}}{\sum_{k} \beta_{k}^{2}}=\frac{\sum_{k} P\left(\tau_{k}\right) \tau_{k}}{\sum_{k} P\left(\tau_{k}\right)}
$$

The RMS delay spread is the square root of the second central moment of the power delay profile and is defined as

$$
\sigma_{\tau}=\sqrt{\overline{\tau^{2}}-(\bar{\tau})^{2}}
$$

where

$$
\bar{\tau}^{2}=\frac{\sum_{k} \beta_{k}^{2} \tau_{k}^{2}}{\sum_{k} \beta_{k}^{2}}=\frac{\sum_{k} P\left(\tau_{k}\right) \tau_{k}^{2}}{\sum_{k} P\left(\tau_{k}\right)}
$$

\subsection{Rake receiver techniques}

Signal reception in a multipath fading channel can be enhanced by a diversity technique using the rake receiver. Rake receivers combine different signal components that have propagated through different paths in the channel. This is a time diversity technique. The combination of different signal components will increase the signal-to-noise ratio (SNR), thus improving the reception performance. There are three major types of rake receivers to be considered here, i.e., I-rake, S-rake, and P-rake. First, I-rake is an ideal rake receiver that captures all of the received signal power by having numbers of fingers equal to the number of multipath components. Using the I-rake, an infinite number of correlators are required to distinguish infinite multipath components. This is difficult to carry out in reality. Second, S-rake is a selective rake receiver which selects $L$ multipath components having largest signal amplitudes. The $S$-rake receiver has much less complexity than the A-rake. Third, P-rake is similar to S-rake. The principle is that the first multipath component will typically be strongest and contain the most received signal power. But, the disadvantage is that it may not correctly choose the strongest multipath components. In this article, we shall take the S-rake receiver. We will evaluate system performance using $L$ as a parameter $(L=1,2,5$, and 8).

\section{Numerical results}

We employ the ray-tracing technique with simplified input layout geometry in the outdoor environment. Figure 4 shows the outdoor environment used for our experiment. There are five buildings from $\mathrm{A}$ to $\mathrm{E}$ in the area. The building heights are 20,30,35, 20, and $25 \mathrm{~m}$, respectively. The transmitting antenna is set on building $\mathrm{B}$ with the horizontal coordinate $(-15 \mathrm{~m},-5 \mathrm{~m})$ and its height is $15 \mathrm{~m}$. The height of the receiving antenna is $1.5 \mathrm{~m}$. The transmitting and receiving antennas are both omni-directional antennas. We consider Areas I, II, III, and IV in the outdoor environment with and without traffic.

In Areas I and II, we take into account the effect of not only the buildings but also the vehicles. Figures 5 and 6 show the dispatch of vehicles in Areas I and II, respectively. The vehicles are placed randomly in Areas I and II and the areas occupied by vehicles are about $10 \%$ of the total area for the rush hour scenario. Two 


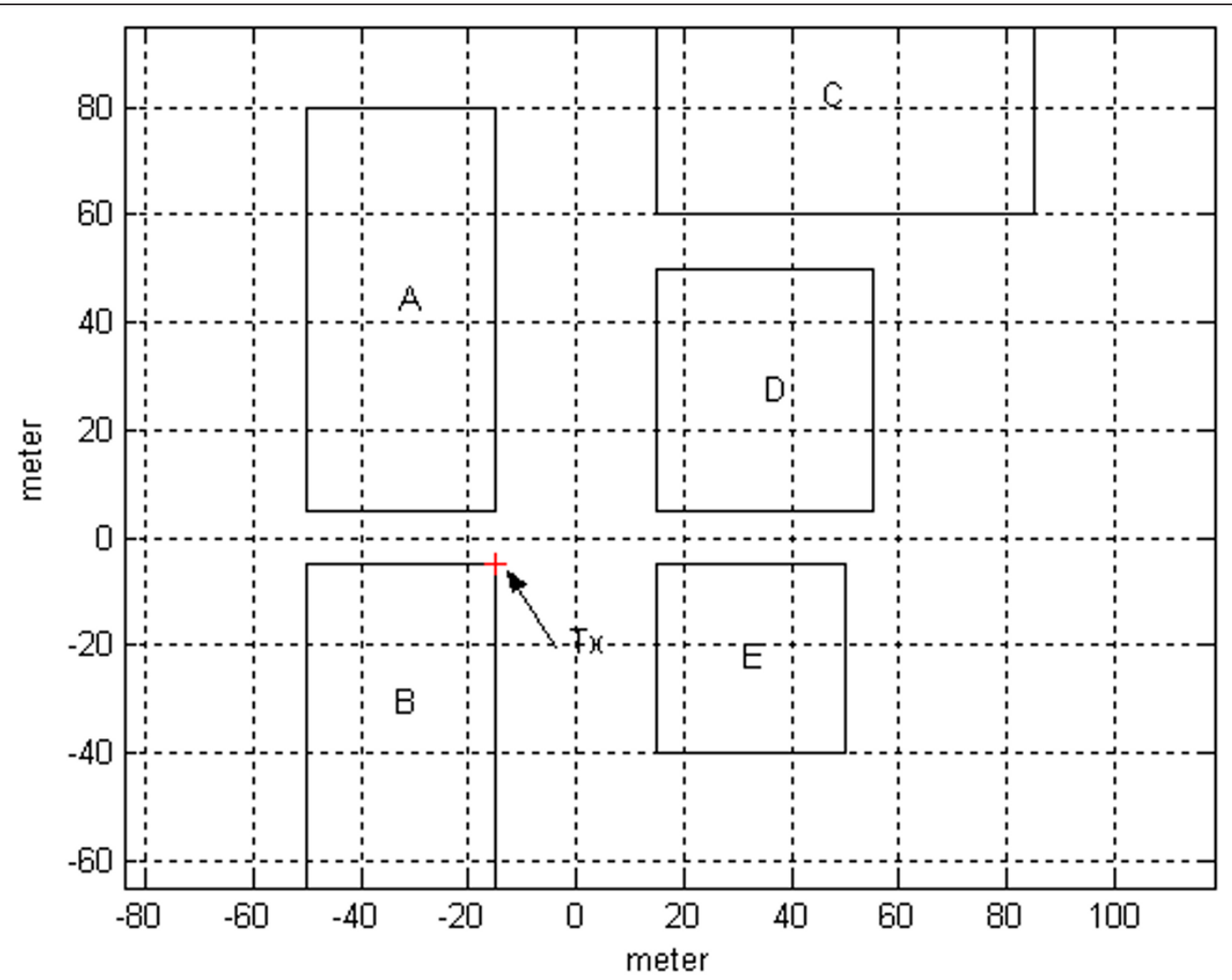

Figure 4 Layout for the simulated outdoor environment.

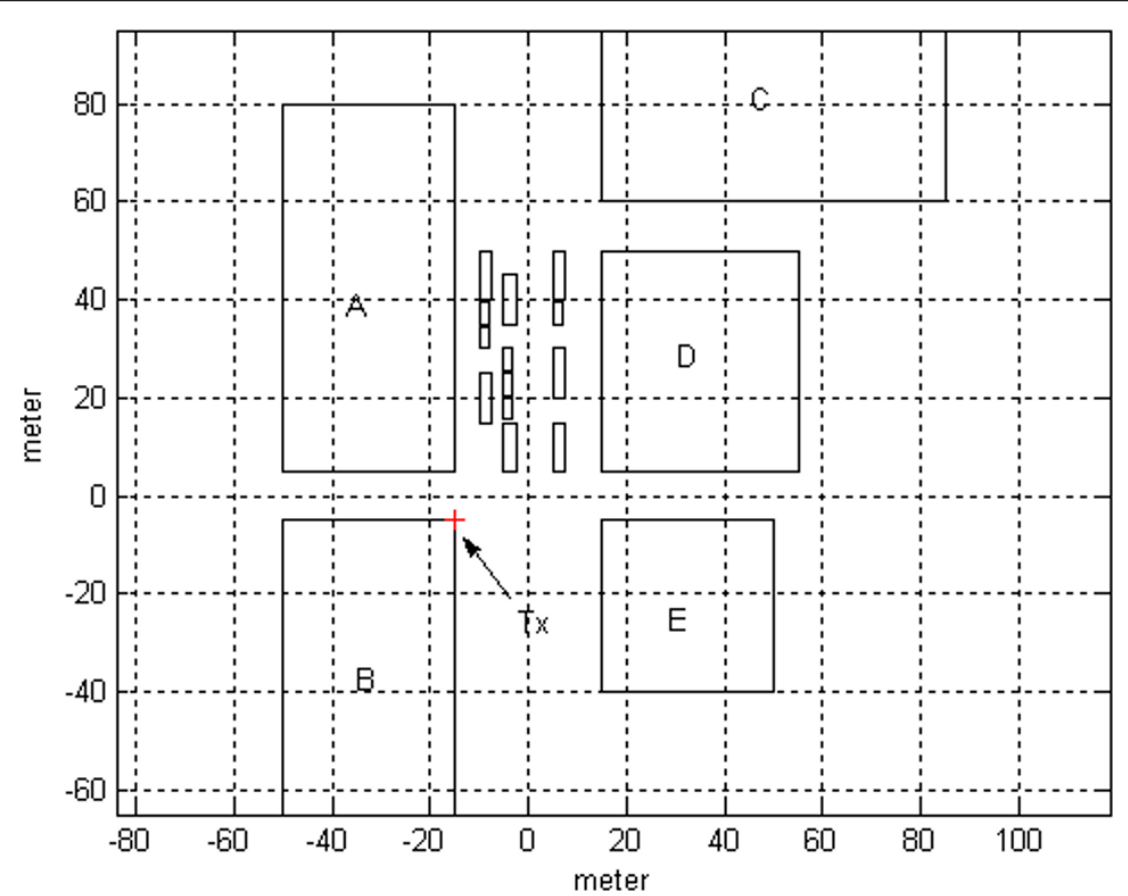

Figure 5 Layout for Area I with traffic. 


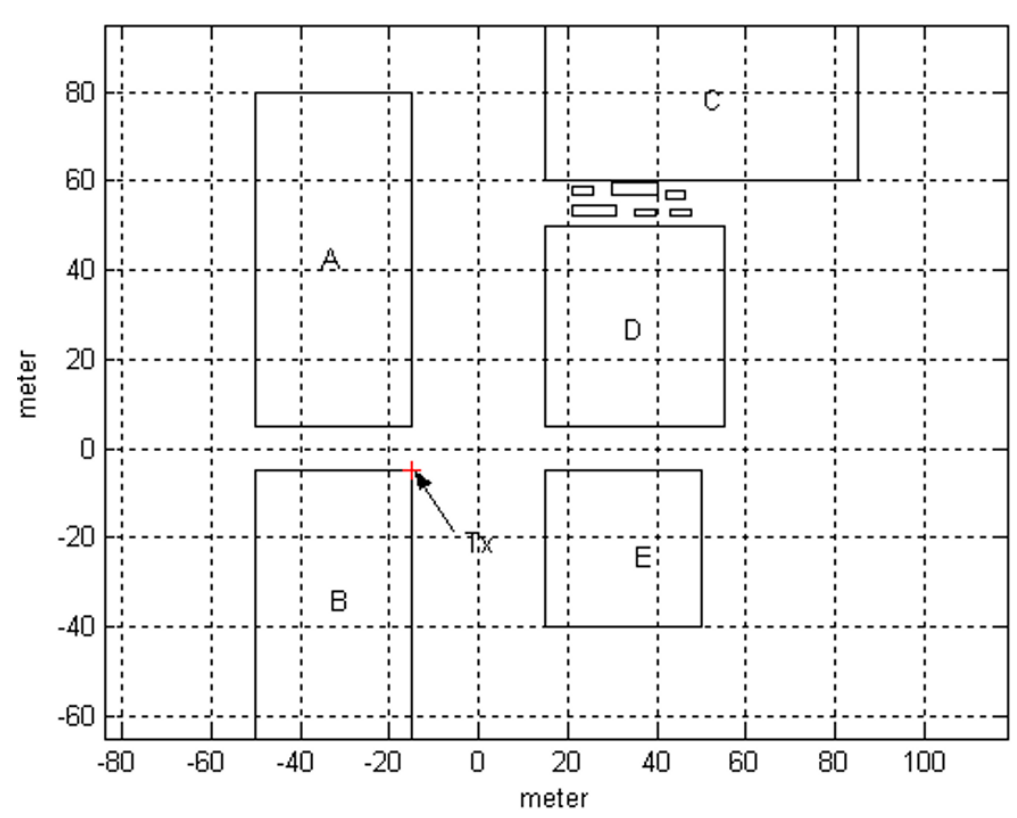

Figure 6 Layout for Area II with traffic.

types of the vehicles are considered. One is a small car with the dimension of $1.5 \mathrm{~m}$ (high) $\times 1.8 \mathrm{~m}$ (wide) $\times 4.5$ $\mathrm{m}$ (long) and the other is a truck with the dimension of $3 \mathrm{~m}$ (high) $\times 2.5 \mathrm{~m}$ (wide) $\times 10 \mathrm{~m}$ (long). In Areas I and II, we simulate over 100 different locations of receivers with uniform distribution. The cases for Areas I and II without traffic are referred to as LOS and NLOS, respectively. We evaluate the RMS delay spread, mean excess delay, BER, and outage probability in our investigations.

Figure 7 shows the outage probability versus SNR with and without traffic in Area I. At 2 Mbps transmission rate, the outage probabilities for $\mathrm{BER}<10^{-5}$ and $\mathrm{SNR}=$ $30 \mathrm{~dB}$ are, respectively, about 6 and $23 \%$ for the cases with and without traffic. Figure 8 shows the outage probability versus SNR in Area II with and without traffic. At

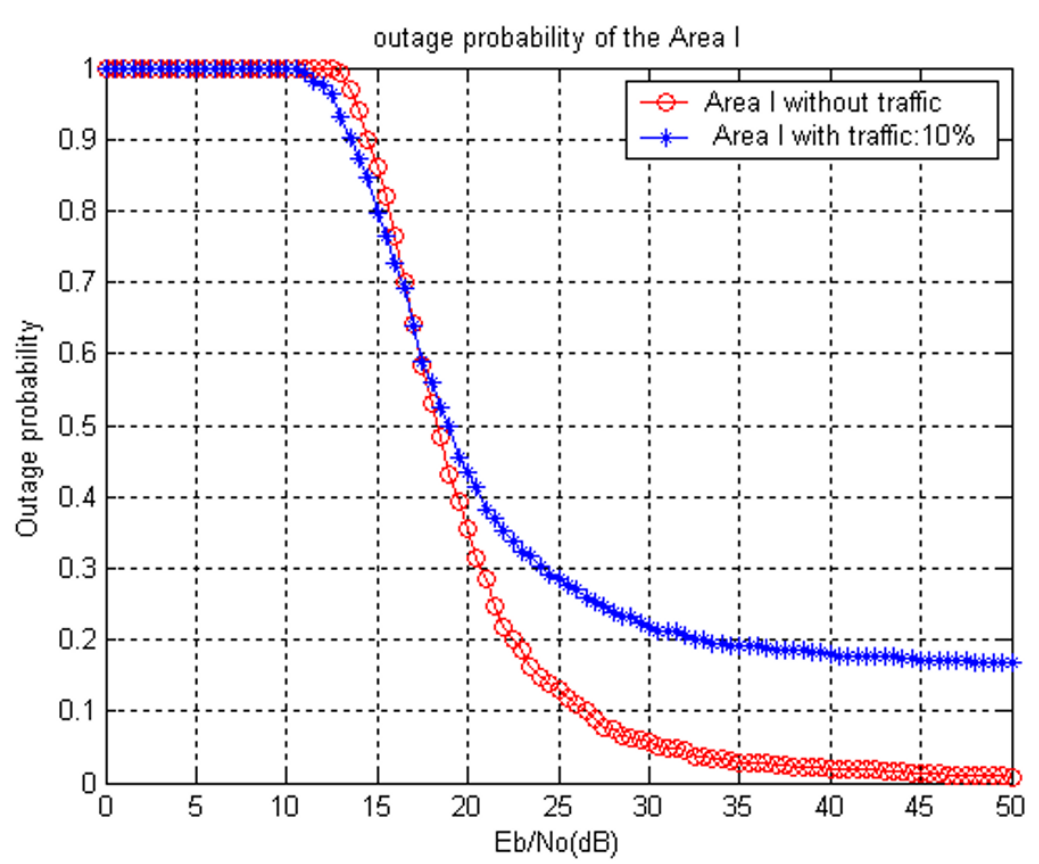

Figure 7 Outage probability versus SNR with and without traffic in Area I. 


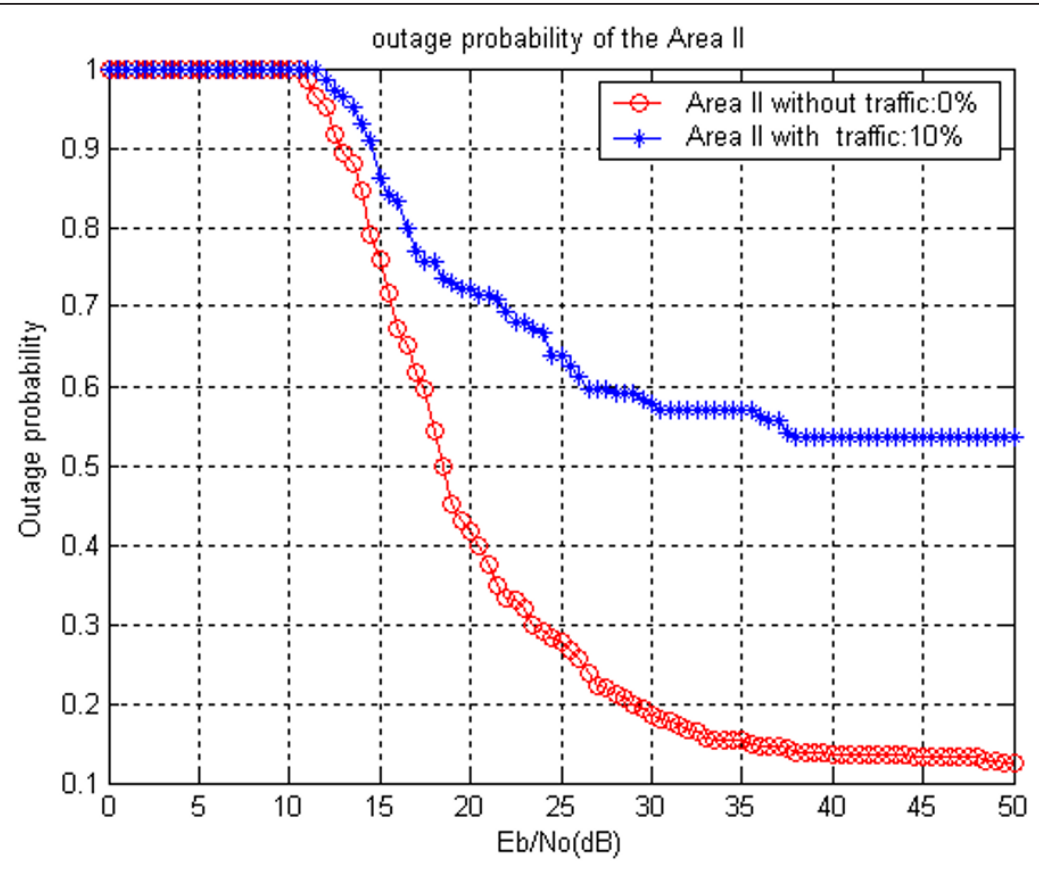

Figure 8 Outage probability versus SNR with and without traffic in Area II.

2 Mbps transmission rate, the outage probabilities for BER $<10^{-5}$ and SNR $=30 \mathrm{~dB}$ are, respectively, about 20 and $58 \%$ for the cases with and without traffic. We observe that the outage probability performance in Area I is better than Area II both with and without traffic. Furthermore, in Area I or II, the outage probability performance without traffic is better than that with traffic by about 17 and 38\%, respectively. The effect of vehicles in Area II is more serious than that in Area I. For Building $\mathrm{D}$, there is no direct transmitting path in Area II and the effect of the vehicles produces more severe multipath and shadow effects to cause larger outage probabilities.

In order to improve the outage probability, we adopt the S-rake in our experiment. Figures 9, 10, 11, and 12 are for

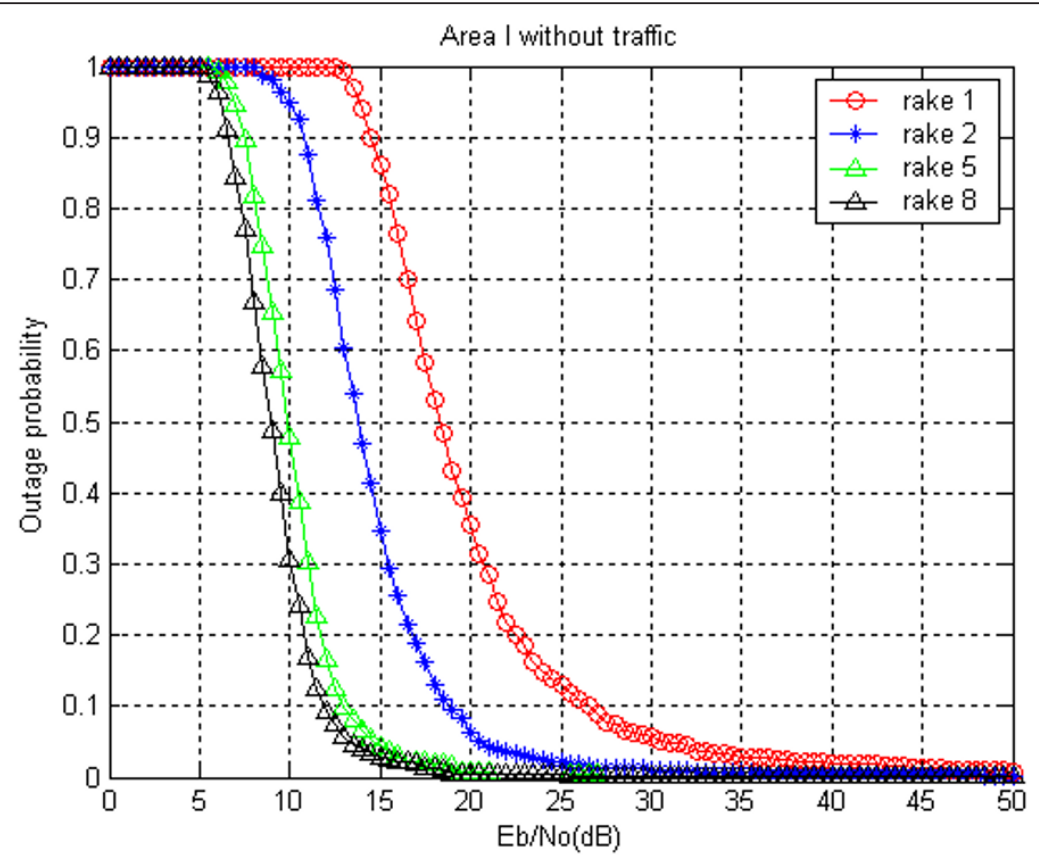

Figure 9 Outage probability versus SNR by different numbers of rake receiver in Area I without traffic. 


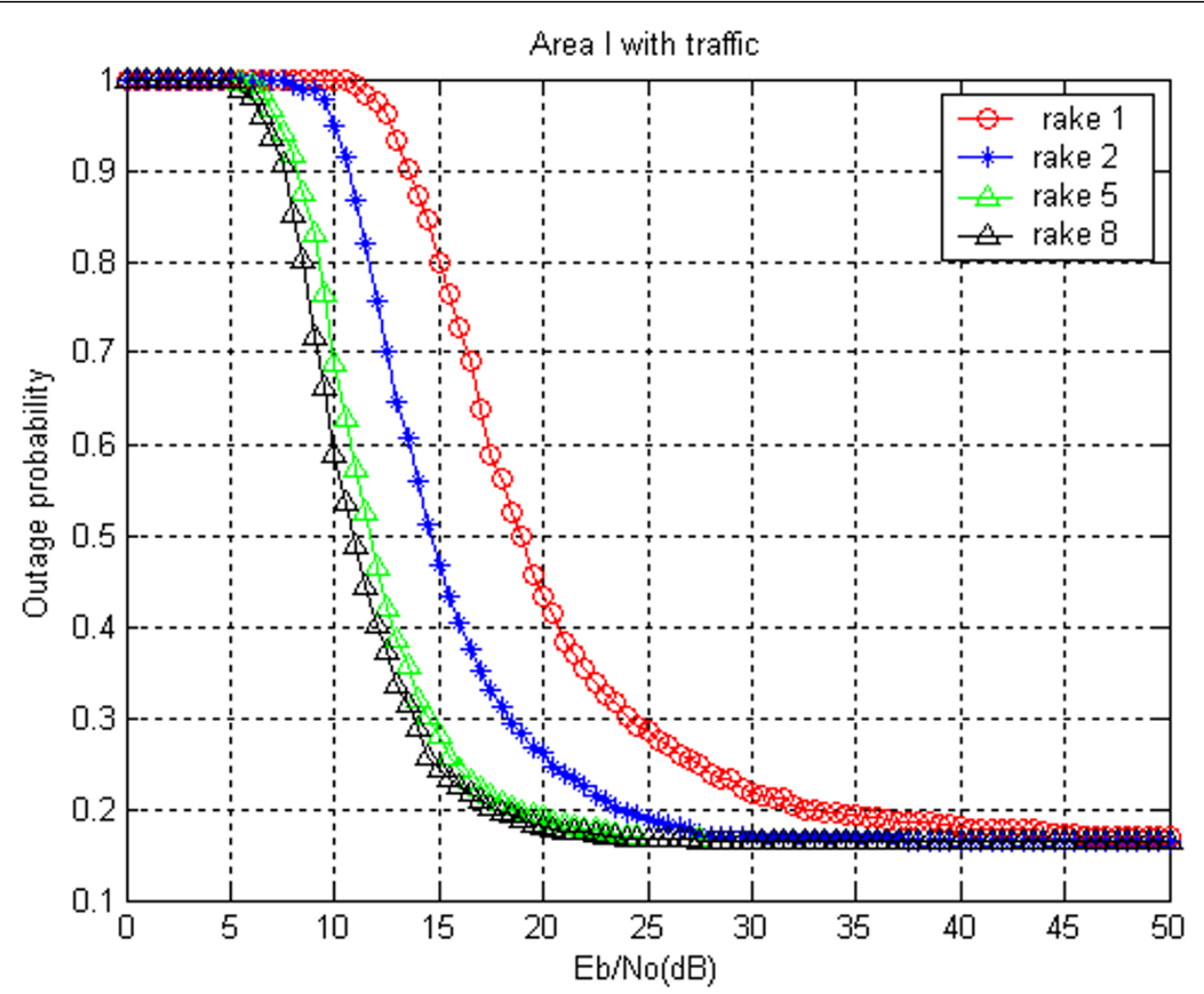

Figure 10 Outage probability versus SNR by different numbers of rake receiver in Area I with traffic.

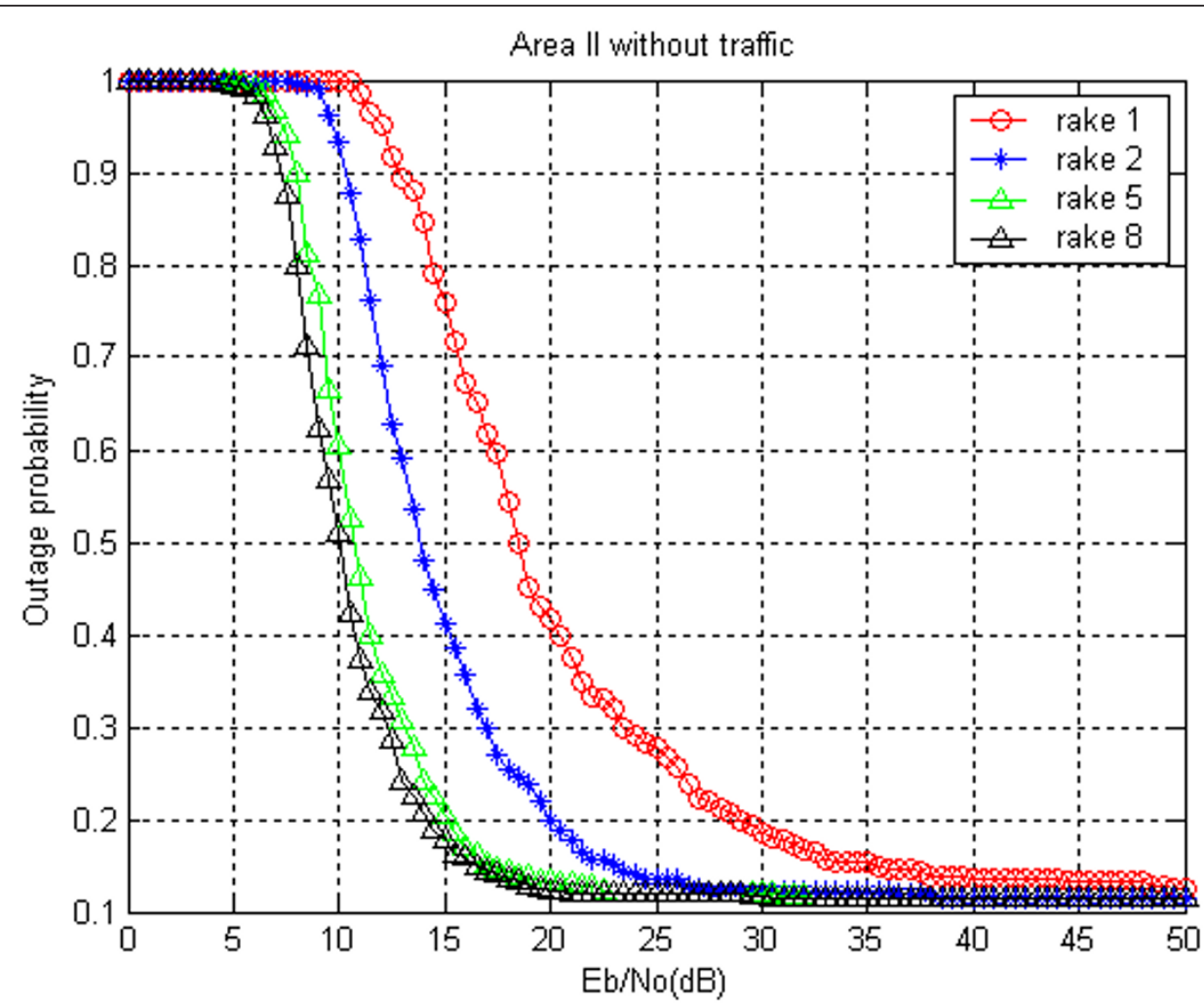

Figure 11 Outage probability versus SNR by different numbers of rake receiver in Area II without traffic. 


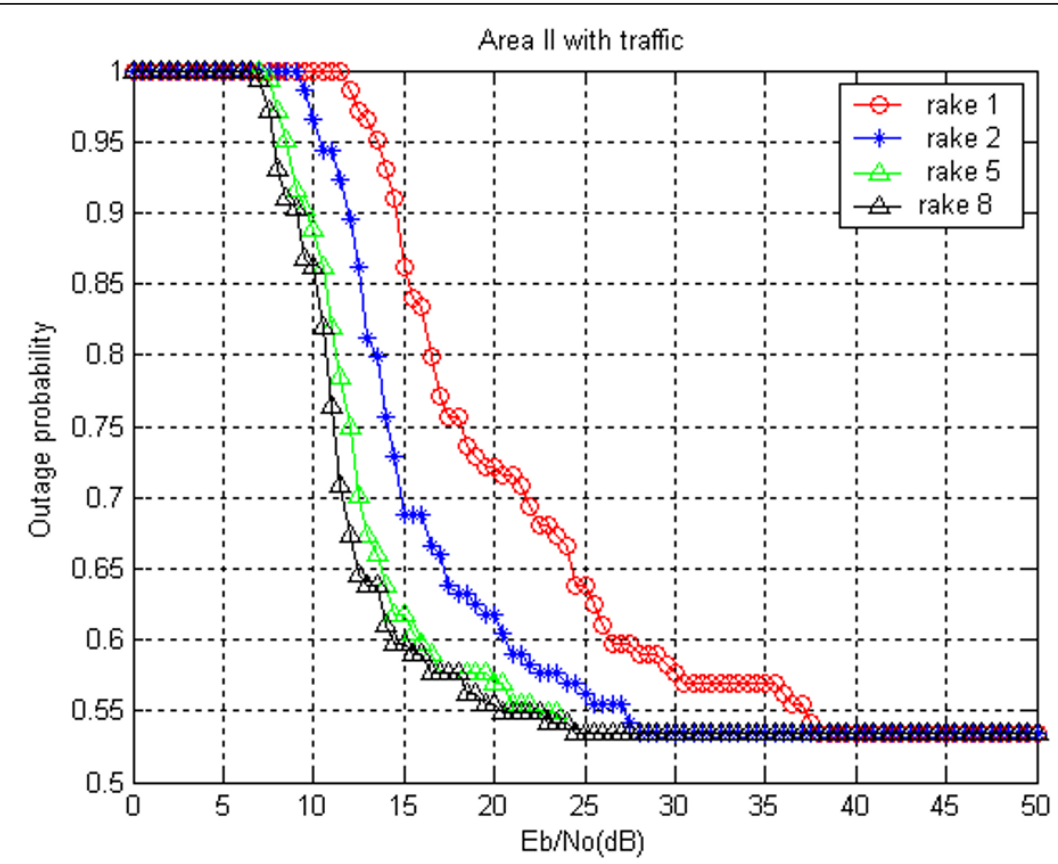

Figure 12 Outage probability versus SNR by different numbers of rake receiver in Area II with traffic.

Areas I and II with and without traffic. We compare the results with different numbers of rakes. In Figures 9 through 12 , the outage probability is reduced more by taking more numbers of rakes. When the number of rakes is more than 5 , outage probability for BER $<10^{-5}$ and $\mathrm{SNR}=$ $20 \mathrm{~dB}$ is reduced by about $20-30 \%$. If the SNR is lower, the performance of rake receiver will be better.

Table 1 shows the excess delay in Areas I and II with and without traffic. Because Area II is the NLOS area, the excess delay of Area II is larger than that of the Area I. Meanwhile, the mean excess delay with traffic is also larger than that without traffic. It is found that the vehicles would increase the excess delay about 60-70 ns. Because direct transmitting rays may be blocked by some vehicles, some transmitting rays reflect several times before they reach the receivers. Consequently, the mean excess delay is increased.

Figures 13 and 14 show cumulative distribution function of RMS delay spread with and without traffic in Areas I and II, respectively. The RMS delay spread $\tau_{\text {rms }}$

Table 1 Mean excess delay with and without traffic in Areas I and II

\begin{tabular}{llll}
\hline Area & Mean (ns) & Max (ns) & Min (ns) \\
\hline Area I without traffic & 147.67 & 198.23 & 73.301 \\
Area I with traffic & 216.08 & 397.08 & 80.411 \\
Area II without traffic & 449.43 & 548.24 & 287.19 \\
Area II with traffic & 509.93 & 691.80 & 339.27 \\
\hline
\end{tabular}

is defined in (13) which measures the effective duration of the channel impulse response. It is a fundamental parameter for evaluating the presence of ISI at the receiver. If the time interval separating two pulses is smaller than $\tau_{\mathrm{rms}}$, ISI is present. The mean RMS delay spreads for the cases with and without traffic are, respectively, about 16.7 and $28.7 \mathrm{~ns}$ in Area I. The mean RMS delay spreads for the cases with and without traffic are, respectively, about 41.5 and 59.6 ns in Area II. Table 2 shows the mean and standard deviation of RMS delay spread. We see that vehicles in Areas I and II increase RMS delay spreads by about 12 and $18.1 \mathrm{~ns}$. Because Area II is of NLOS and the block of vehicles will cause more severe multipath effect and shadow effect. This is why RMS delay spread in Area II is larger than that in Area I. It is thus clear to see the different effects caused by the vehicles in the Areas I and II.

We now consider Areas III and IV in the outdoor environment with traffic. In Areas III and IV, we take into account the effect of not only the buildings but also the vehicles. Figures 15 and 16 show the dispatch of vehicles in Areas III and IV, respectively.

Our goal is to realize the characteristics of wireless communication system in outdoor environments. We use the ray tracing model to simulate the environments in wireless communication systems. Moreover, taking advantage of differencnt techniques to improve the performance of wireless communications systems different antenna arrays and rake receivers. 


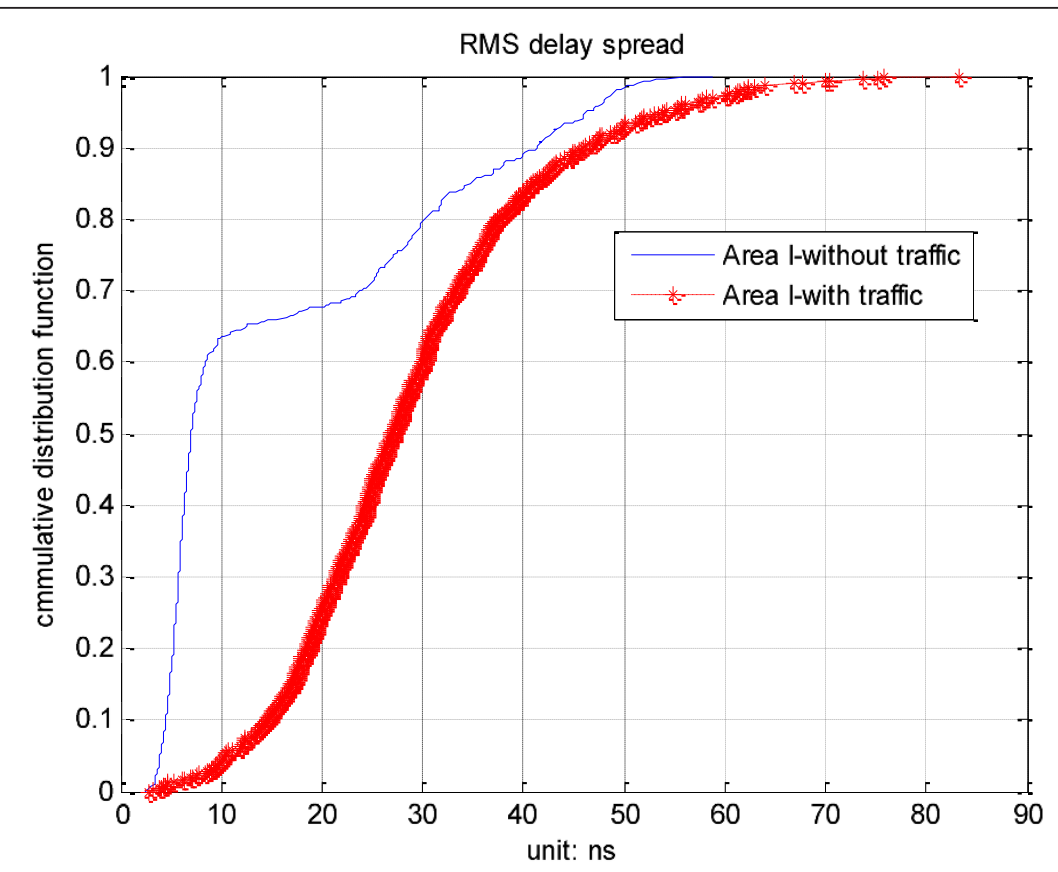

Figure 13 Cumulative distribution function versus RMS delay spread with and without traffic in Area I.

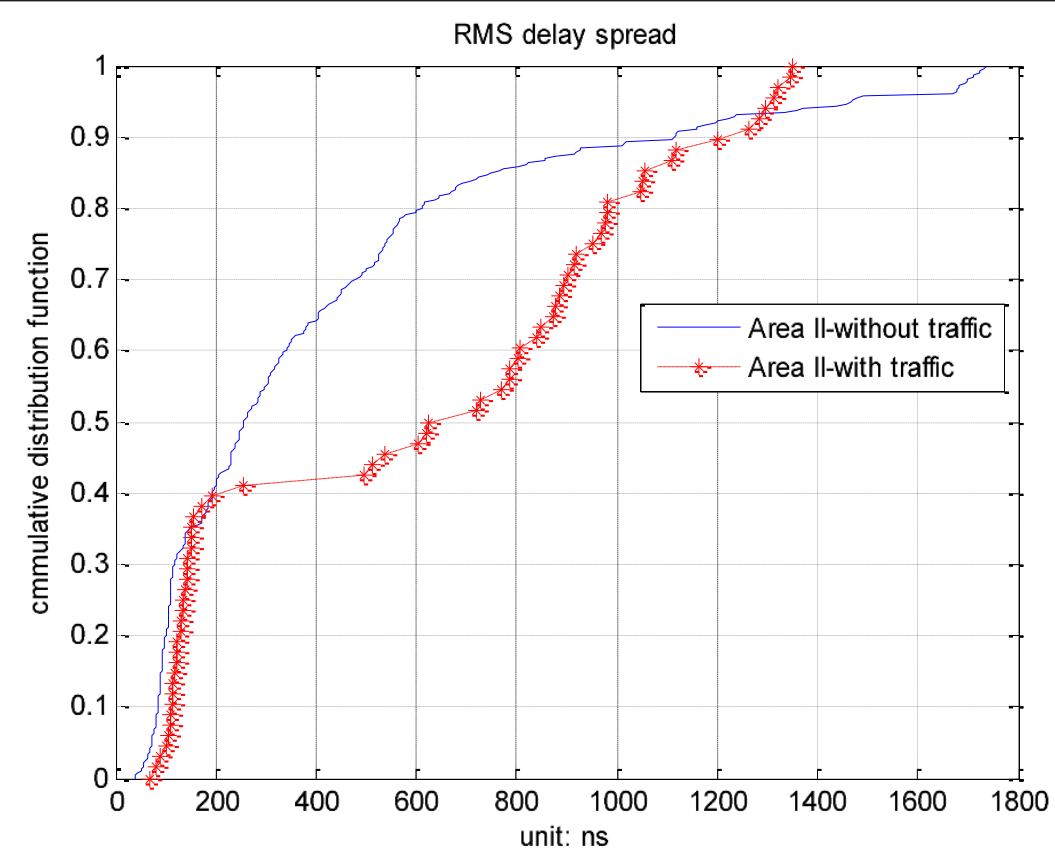

Figure 14 Cumulative distribution function versus RMS delay spread with and without traffic in Area II.

Table 2 RMS delay spread with and without traffic in the Area I and II

\begin{tabular}{lllll}
\hline Area & \multicolumn{2}{l}{ RMS delay spread } & & \\
\cline { 2 - 5 } & Mean (ns) & Standard deviation (ns) & RMS max (ns) & RMS min (ns) \\
\hline Area I without traffic & 16.72 & 12.99 & 58.89 & 1.41 \\
Area I with traffic & 28.70 & 14.64 & 83.21 & 2.46 \\
Area II without traffic & 41.53 & 42.20 & 173.55 & 3.78 \\
Area II with traffic & 59.69 & 43.87 & 134.87 & 6.95 \\
\hline
\end{tabular}




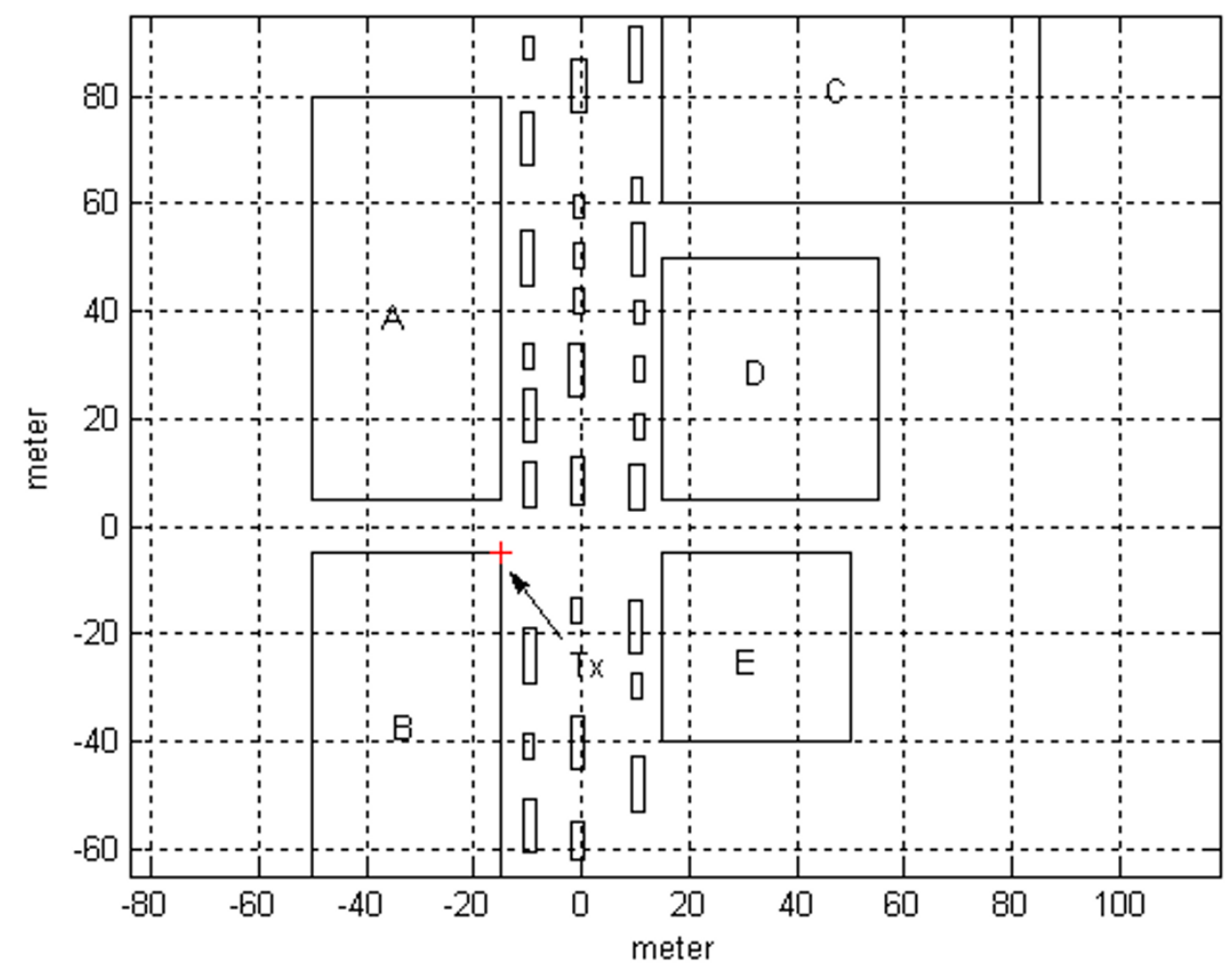

Figure 15 Layout for Area III with traffic.

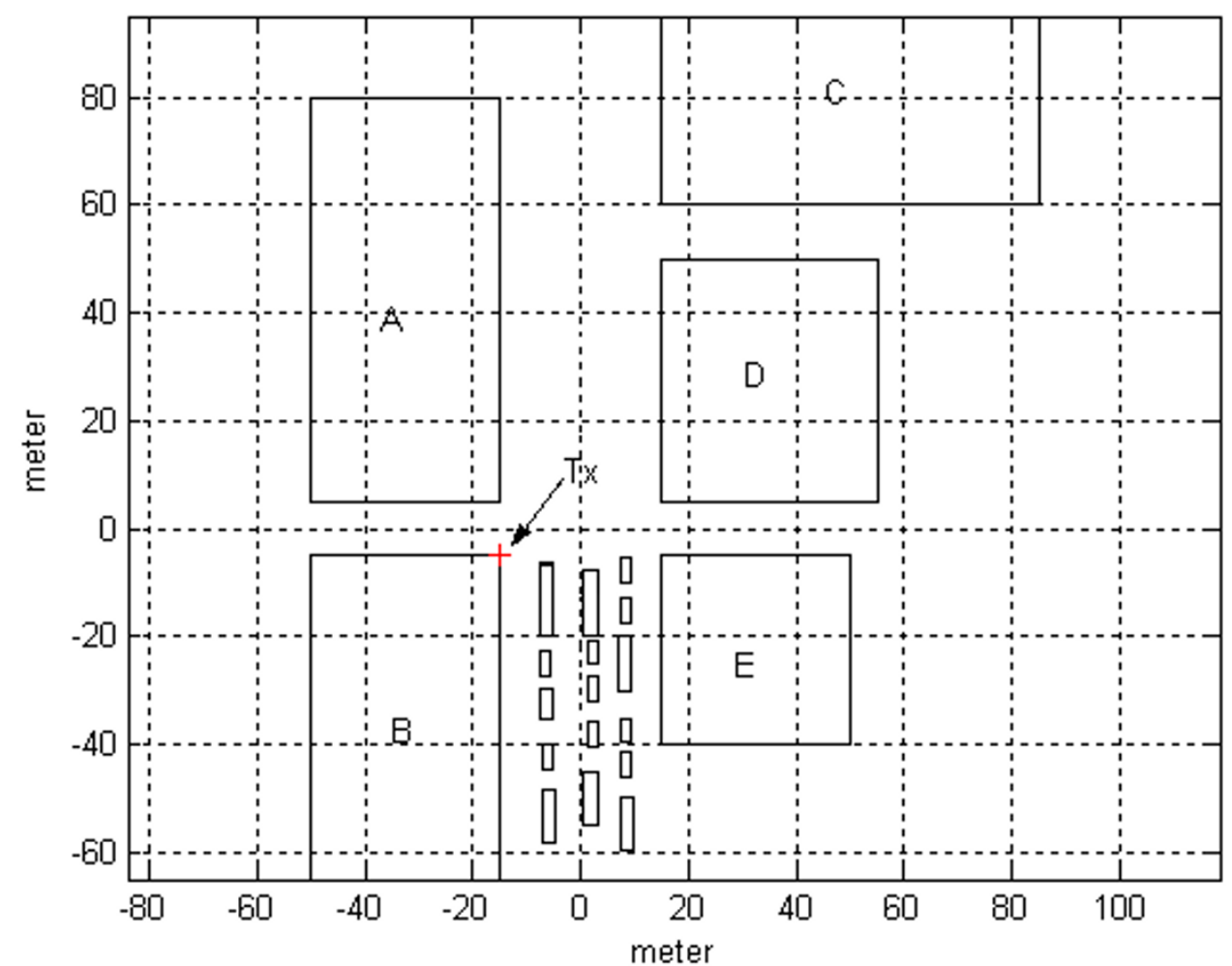




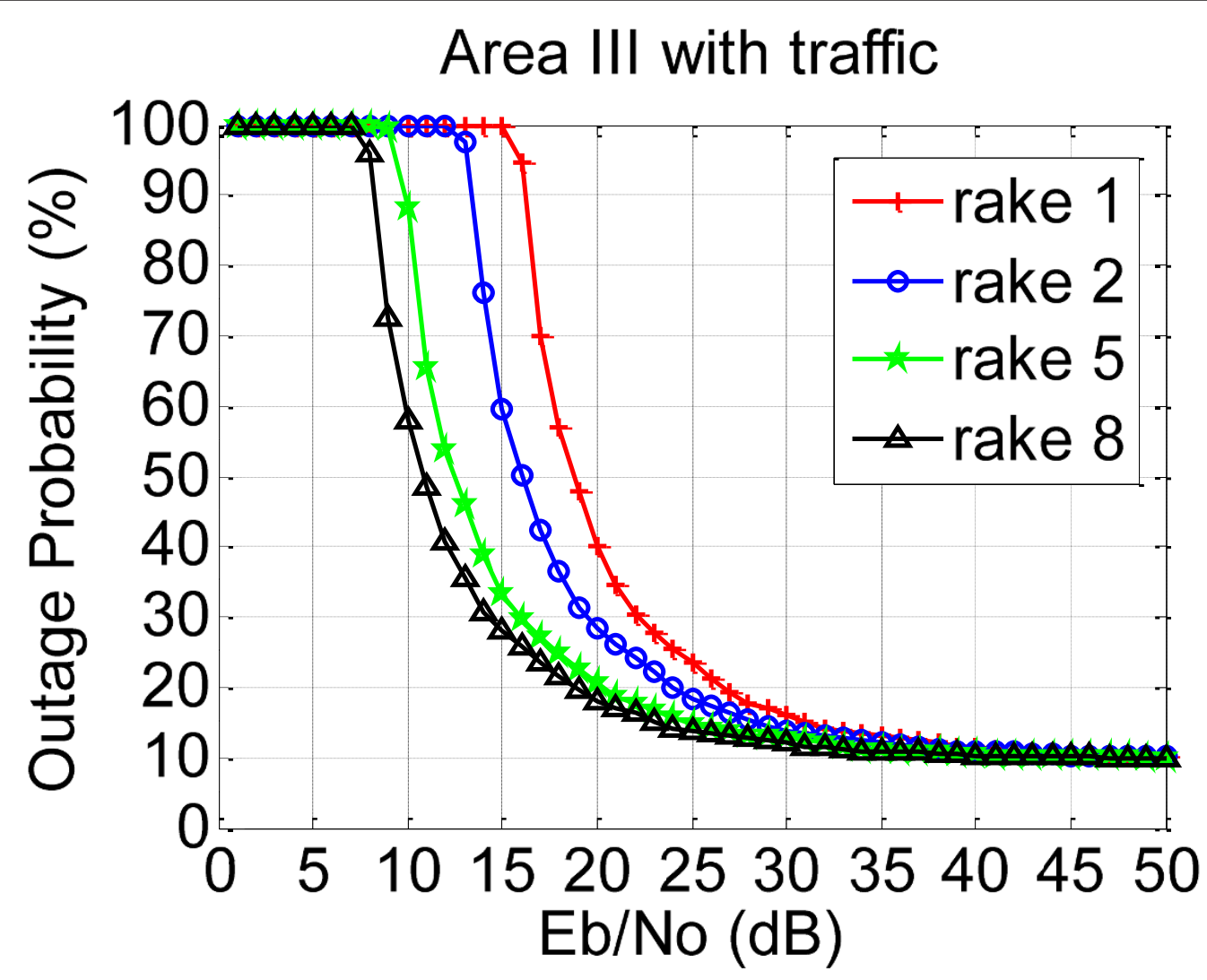

Figure 17 Outage probability versus SNR using different numbers of rake receiver in Area III with traffic.

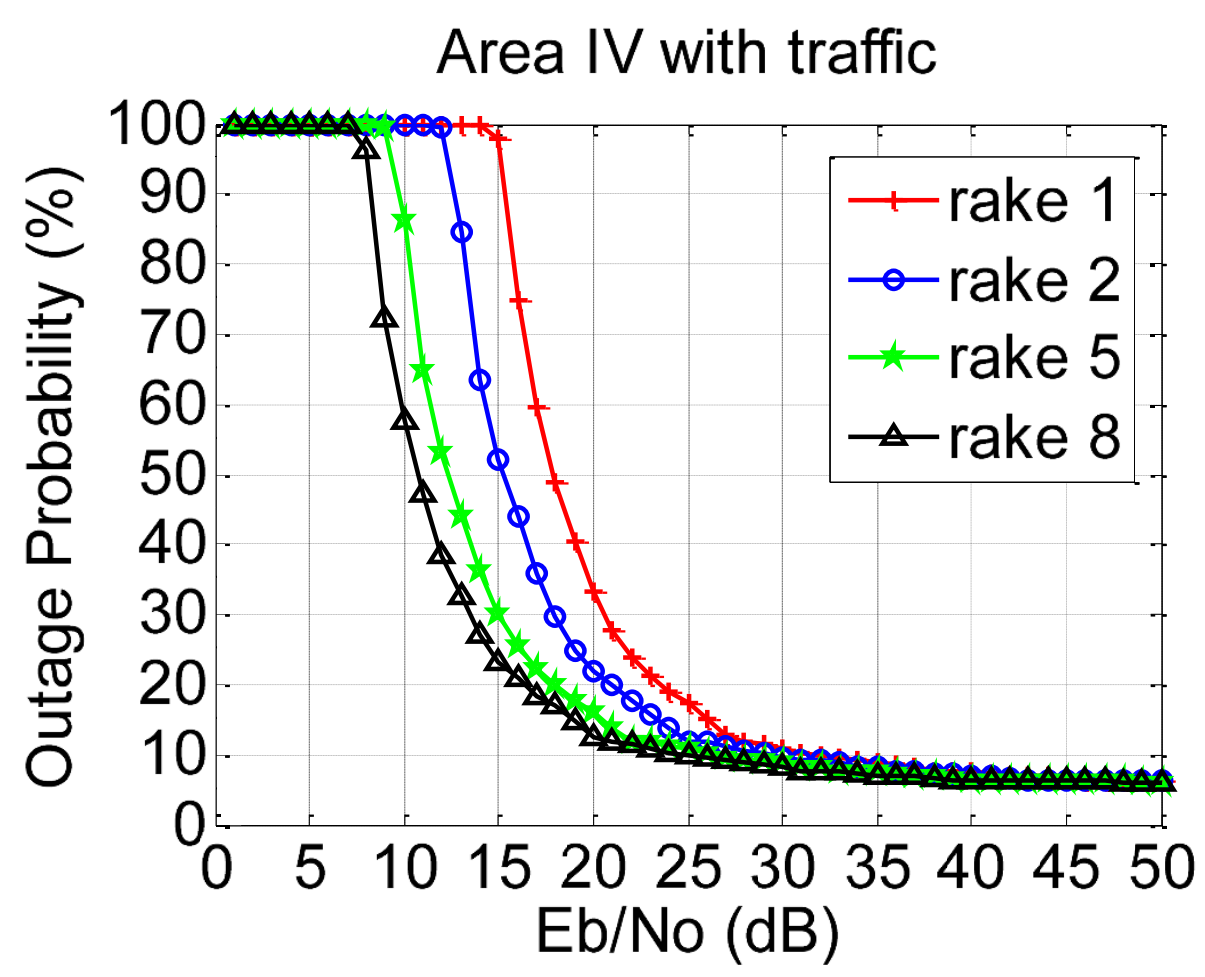

Figure 18 Outage probability versus SNR by different numbers of rake receiver in Area IV with traffic. 
We considered the conditions with and without traffic in the UWB system in this article. We adopt the S-rake with different numbers " $L$ " of rakes in our simulations to reduce the BER and improve outage probabilities.

In order to improve the outage probability, we again adopt the S-rake in our experiment. Figures 17 and 18 are given for Areas III and IV with and without traffic. We compare the results with different numbers of rakes. In Figures 17 and 18, the outage probability is reduced more by taking more numbers of rakes. For BER $<10^{-5}$, at $\mathrm{SNR}=20 \mathrm{~dB}$, the outage probability will be reduced by about $20 \%$ when the number of rakes is increased from 1 to 5 . Further increase of the number of rakes will not improve the outage probability much.

\section{Conclusions}

UWB outdoor communication characteristics with and without traffic are presented. By using the impulse response of the multipath channel, the BER, mean excess delay, and RMS delay spread for UWB outdoor communication are evaluated. Also, outage probabilities are calculated for various different scenarios. Cases with and without traffic in the UWB outdoor environment are considered. Moreover, we use the rake receiver technique to improve the performance of outage probability.

\section{Author details}

${ }^{1}$ Electrical Engineering Department, Tamkang University, Tamsui Dist, New Taipei City 25137, Taiwan ${ }^{2}$ Department of Computer and Communication Engineering Dapartment, Taipei College of Maritime Technology, Tamsui Dist, New Taipei City 25137, Taiwan

\section{Competing interests}

The authors declare that they have no competing interests.

Received: 8 July 2011 Accepted: 7 March 2012 Published: 7 March 2012

\section{References}

1. First report and order, revision of part 15 of the communication's rules regarding ultra-wideband transmission systems. FCC, ET Docket 98-153 (February 2002)

2. AF Molisch., et al, IEEE 802.15.4a Channel Model - Final Report. http://www. ieee802.org/15/pub/04/15-04-0662-02-004a-channel-model-final-report-r1. pdf (Sept 2004)

3. K Siwiak, P Withington, S Phelan, Ultra-wideband radio: the emergence of an important new technology. in IEEE VTS 53rd Vehicular Technology Conference, 2001. VTC 2001 Spring, Rhodes, Greece. 2, 1169-1172 (May 2001)

4. K Siwiak, Ultra-wideband radio: introducing a new technology. in IEEE VTS 53rd Vehicular Technology Conference, 2001. VTC 2001 Spring, Rhodes, Greece. 2, 1088-1093 (May 2001)

5. CA Corral, S Emami, G Rasor, A weighted multiple-frequency method for ultra-wideband outdoor coverage prediction, in Consumer Communications and Networking Conference, 2005. CCNC. 2005 Second IEEE, Las Vegas, Nevada, USA, pp. 461-465 (3-6 January 2005)

6. S Emami, CA Corral, G Rasor, Ultra-wideband outdoor channel modeling using ray tracing techniques, in Consumer Communications and Networking Conference, 2005. CCNC. 2005 Second IEEE, Las Vegas, Nevada, USA, pp. 466-470 (3-6 January 2005)

7. SH Chen, SK Jeng, An SBR/image approach for indoor radio propagation in a corridor. IEICE Trans Electron. E78-C, 1058-1062 (1995)
8. SH Chen, SK Jeng, SBR image approach for radio wave propagation in tunnels with and without traffic. IEEE Trans Veh Technol. 45, 570-578 (1996). doi:10.1109/25.533772

9. S Loredo, A Rodríguez-Alonso, RP Torres, Indoor MIMO channel modeling by rigorous GO/UTD-based ray tracing. IEEE Trans Veh Technol. 57(2), 680-692 (2008)

10. CA Balanis, Advanced Engineering Electromagnetics (USA John Wiley \& Sons, 1989)

11. I Oppermann, M Hamalainen, J linatti, UWB Theory and Applications (UK John Wiley \& Sons, 2004)

12. EW Kamen, BS Heck, Fundamentals of Signals and Systems Using the Web and Matlab, Upper Saddle River, New Jersey, (Prentice-Hall, 2000)

13. AAM Saleh, RA Valenzuela, A statistical model for indoor multipath propagation. IEEE J Sel Areas Commun. 5, 128-137 (1987)

14. T Zhi, GB Giannakis, BER sensitivity to mistiming in ultra-wideband impulse radios-part I: nonrandom channels. IEEE Trans Signal Process. 53(4), 1550-1560 (2005)

15. CH Chen, CL Liu, CC Chiu, TM Hu, Ultra-wideband channel calculation by SBR/image techniques for indoor communication. J Electromagn Waves Appl. 20(1), 2169-2179 (2006)

16. SH Liao, MH Ho, CC Chiu, CH Lin, Optimal Relay Antenna Location in Indoor Environment Using Particle Swarm Optimizer and Genetic Algorithm. Wireless Personal Communications. 62(3), 599-615 (July 2012). doi:10.1007/s11277-010-0083-8

17. CC Chiu, YT YKao, SH Liao, YF Huang, 'UWB Communication Characteristics for Different Materials and Shapes of the Stairs. Journal of Communications. 6(8), 628-632 (Nov. 2011)

18. SH Liao, HP Chen, CC Chiu, CL Liu, Channel Capacities of Indoor MIMOUWB Transmission for Different Material Partitions. Tamkang Journal of Science and Engineering. 14(1), 49-63 (Mar. 2011)

19. SH Liao, CC Chiu, MH Ho, CL Liu, Channel Capacity of Multiple-Input Multiple-Output Ultra Wide Band Systems with Single Co-channel Interference. International Journal of Communication Systems. 23(12), 1600-1612 (Dec. 2010). doi:10.1002/dac.1131

20. SH Liao, MH Ho, CC Chiu, Bit Error Rate Reduction for Multiusers by Smart UWB Antenna Array. Progress In Electromagnetic Research C Vol. 15. PIER C 16 85-98 (Oct. 2010)

21. $\mathrm{MH} \mathrm{Ho}, \mathrm{SH}$ Liao, CC Chiu, UWB Communication Characteristics for Different Distribution of People and Various Materials of Walls. Tamkang Journal of Science and Engineering. 13(3), 315-326 (Sep. 2010)

22. $\mathrm{MH} \mathrm{Ho}$, SH Liao, CC Chiu, A Novel Smart UWB Antenna Array Design by PSO. Progress In Electromagnetic Research C PIER C 15. 15, 103-115 (Aug 2010)

23. CL Liu, MH Ho, CC Chiu, CY Cheng, A Comparison of UWB Communication Characteristics for Various Corridors. ACTA International Journal of Modelling and Simulation. 30(2), 172-177 (May 2010)

24. CL Liu, CC Chiu, SH Liao, YS Chen, Impact of Metallic Furniture on UWB Channel Statistical Characteristics. Tamkang Journal of Science and Engineering. 12(3), 271-278 (Sept. 2009)

doi:10.1186/1687-1499-2012-92

Cite this article as: Chiu et al:: Ultra-wideband outdoor communication characteristics with and without traffic. EURASIP Journal on Wireless Communications and Networking 2012 2012:92

\section{Submit your manuscript to a SpringerOpen ${ }^{\circ}$ journal and benefit from:}

- Convenient online submission

- Rigorous peer review

- Immediate publication on acceptance

- Open access: articles freely available online

- High visibility within the field

- Retaining the copyright to your article

Submit your next manuscript at $>$ springeropen.com 